\title{
Macroeconomic Effects of Loan Supply Shocks: Empirical Evidence for Peru*
}

Jefferson Martínez+, Gabriel Rodríguez

* This paper is drawn from Jefferson Martínez's Thesis to obtain a Master's degree in Economics from the Pontificia Universidad Católica del Perú (PUCP). We thank the useful comments by Pau Castillo B. (Central Reserve Bank of Peru-BCRP and PUCP), Oscar Dancourt (PUCP), participants in the 36th BCRP Meeting of Economist (October 30-31, 2018, Lima, Peru), an anonymous Referee and the Editor Fausto Hernández. The views expressed in this paper are those of the authors and do not reflect necessarily the position of the Central Reserve Bank of Peru. Any remaining errors are our responsibility.

+ Pontificia Universidad Católica del Perú and Central Reserve Bank of Peru. E-Mail Addresses: jimartinezs@pucp.edu.pe, jefferson.martinez@bcrp.gob.pe.

* Address for Correspondence: Gabriel Rodríguez Department of Economics, Pontificia Universidad Católica del Perú, 1801 Avenida Universitaria, Lima 32, Perú, Telephone: +511-626-2000 (4998). E-Mail Address: gabriel.rodriguez@pucp. edu.pe. ORCID ID: https://orcid.org/0000 0003-1174-9642

\section{Abstract}

This paper quantifies and assesses the impact of an adverse loan supply (LS) shock on Peru's main macroeconomic aggregates using a Bayesian vector autoregressive (BVAR) model in combination with an identification scheme with sign restrictions. The main results indicate that an adverse LS shock: (i) reduces credit and real GDP growth by 372 and 75 basis points in the impact period, respectively; (ii) explains $11.2 \%$ of real GDP growth variability on average over the following 20 quarters; and (iii) explained a 180-basis point fall in real GDP growth on average during 2009Q1-2010Q1 in the wake of the Global Financial Crisis (GFC). Additionally, the sensitivity analysis shows that the results are robust to alternative identification schemes with sign restrictions; and that an adverse LS shock has a greater impact on non-primary real GDP growth.

Keywords: Banking System, Loan Supply Shock, Bayesian Autoregressive Vector Model, Sign Restrictions, Peruvian Economy.

JEL Classification: G1 1, E32, E51. 


\section{Introduction}

Peru has maintained sustained growth since the mid-1990s, except for 1998 and 2008-2009 in the context of the Asian Crisis and the Great Financial Crisis (GFC), respectively. The Central Reserve Bank of Peru (BCRP) reports 4.5\% annual growth on average over the last 20 years. Castillo and Salas (2010), Nolazco et al. (2016), and Rodríguez et al. (2018) indicate that favorable external shocks during the second half of the 2000s contributed significantly to solid growth. However, it may be misleading to underestimate the role of domestic demand. Private investment in real terms remained above 13\% of GDP since 1994 (above 15\% since 2007). This is important, as private investment is the aggregate demand component that brings together the financial and real sectors of the economy.

Private companies have two potential sources of financing: the financial system and the stock exchange market. As the latter is not considerably developed in Peru, the former provides companies with the necessary resources to carry out their investments. Moreover, banking entities have the highest participation in the financial system. The Superintendence of Banking, Insurance, and Pension Funds (SBS) reports that bank loans over the last 10 years represented $80 \%-90 \%$ of total financial system loans. Since 2005, they increased in a sustained manner and began to decelerate at end-2009 in connection with the GFC. BCRP data indicate that domestic-currency bank loans decelerated year-on-year from 47.9\% in November 2008 to 10.9\% in January 2010. Since then, loan growth has recovered, but remains below pre-GFG levels. The data show a strong relationship between real GDP and bank credit growth over the last 20 years, as noted by Espino (2013).

The conventional theoretical literature has not produced a model for assessing the impact of loan supply (LS) shocks on the economy, except indirectly Bernanke and Blinder (1988), who attach the banking system to a classical IS/LM model. One of the most important features of this model is that the bond market and the banking system compete to finance company investments. Dancourt (2012) proposes an adaptation of this model for a small open economy, with the short-run interest rate as policy instrument. The model suggests that in the short run a contractionary ${ }^{1}$ LS shock decreases output, prices, the policy interest rate, and bank credit; and increases bank lending rates.

The literature includes studies using micro-founded models to analyze the role of financial system funding in the business cycle, although on the credit demand side. Bernanke et al. (1996, 1999) use a model incorporating the financial accelerator to suggest that lenders' request of collateral (i.e., wealth) to compensate for their lack of information about borrowers (i.e., financing costs are inversely related to borrowers' wealth) magnifies the financial system's contribution to the business cycle. The model shows that individual wealth increases, financial costs drop, and borrowers gain access to higher financing in boom periods. Conversely, individual wealth decreases, financial costs rise, and borrowers' access to financing falls in recession periods. In sum, lenders and financial costs magnify the business cycle. Along the same lines, Kiyotaki and Moore (1997) identify companies' capital stock (used as collateral to borrow) as an element that magnifies business cycle fluctuations. The model suggests that an adverse technological shock simultaneously reduces output and the demand for production factors, notably capital assets, in turn deteriorating their value as collateral. As a result, companies' access to credit decreases, thereby deepening the recession phase. A favorable technological shock causes the opposite behavior.

There is still a need of a model for assessing the impact of an LS shock on the economy. Dynamic stochastic general equilibrium (DSGE) models provide solid technical support in producing empirical evidence. One of the first studies attaching a banking system to a DSGE model is Goodfriend and McCallum (2007), who identify the impact of two kinds of LS shocks: a productivity shock on loan monitoring and a shock on effective loan collateral. In particular,

1 In the theoretical model, an adverse LS shock is represented by a reduction in bankers' marginal propensity to lend. 
a negative shock of the latter kind is interpreted as a financial stress situation; and the authors suggest that it results in a fall in output and inflation.

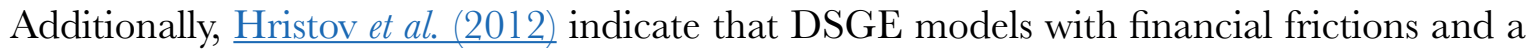
participatory credit market provide an insight into the impact of LS shocks on macroeconomic aggregates. In particular, Atta-Mensah and Dib (2008), Gilchrist et al. (2009), Gerali et al. (2010), Gúrdia and Woodford (2010), and Gertler and Karadi (2011) find that an adverse LS shock has a contractionary impact on credit volume and output, and increases lending rates.

However, there is no consensus among the authors mentioned above about the impact on inflation. For example, Atta-Mensah and Dib (2008) argue that companies request loans to pay for intermediate goods. If loan volumes decrease and financing costs rise, intermediate goods become more costly, thereby increasing marginal costs and prices. In contrast, Gilchrist et al. (2009), Gertler and Karadi (2011), and Cúrdia and Woodford (2010) find that a contractionary supply shock decreases inflation.

For its part, empirical literature on LS shocks is relatively recent. The most frequently used methodology is using vector models to assess the impact from LS shocks. A seminal paper by Groen (2004) uses a structural vector autoregressive model (SVAR) with an identification scheme for short- and long-run restrictions, which suggests that LS shocks are significant in explaining GDP behavior in the U.S. and the Netherlands, although with a small participation. Additionally, Musso et al. (2011) use a SVAR model to assess the relevance of monetary policy (MP), LS, and housing demand shocks in the U.S. and the Eurozone. They suggest that the impact from an LS shock is significant in both economic areas, although higher in the Eurozone.

Three recent works use sign restrictions to identify LS shocks. Busch et al. (2010) estimate a Bayesian VAR (BVAR) model for Germany to identify the impact of MP and LS shocks. The impulse response functions (IRFs) show that LS shocks have a significant effect on output over two years, with a maximum in the seventh quarter; while the effect of MP shocks seems to be neutral in the impact period but grows over the next quarters. Hristov et al. (2012) estimate a panel BVAR for 11 Eurozone countries, with sign restrictions for the aggregate demand (AD), aggregate supply (AS), MP, and LS shocks. The forecast error variance decomposition (FEVD) shows that LS shocks explain around 15\% of output variability, while historical decomposition (HD) indicates that, during the GFC, in the absence of LS shocks, output would have grown $0.6 \%$ $2.1 \%$ more than it actually did. Gambetti and Musso (2017) use a time-varying parameter VAR model with stochastic volatility (TVP-VAR-SV) to suggest that LS shocks are important during recessions in the Eurozone, the UK, and the U.S.; i.e., LS shocks explained around half of the fall in the real GDP growth rate during 2008-2009 in the Eurozone and the U.S., and probably around three-quarters in the UK.

Additionally, Guevara and Rodríguez $(2018,2020)$ assess the role of LS shocks in Pacific Alliance $(\mathrm{PA})^{2}$ countries using information from the 1990s to mid-2017. Average IRF results indicate that LS shocks have a significant impact on output growth in PA countries, while the FEVD suggests that they explain around 16\% of output growth variance. Moreover, the authors find that the end-1990s LS shock reduced real output growth by around 0.67 percentage points in Chile, Colombia, and Peru, while the contractionary effect materialized in Mexico only after 2000.

The stylized facts suggest that the behavior of bank credit influences Peru's business cycle. This paper discusses the impact of a LS shock on real output growth, inflation, credit growth, and the policy interest rate. We use a BVAR model with restrictions on the signs of structural shocks, in line with macroeconomic theory. The empirical methodology and the sign restrictions are based on Hristov et. al. (2012). Additionally, we propose three alternative identification schemes to test for robustness. Three main findings emerge from the exercise. First, the IRFs show that an adverse

2 Member countries are Chile, Colombia, Mexico, and Peru. 
LS shock reduces credit and real output growth by 372 and 75 basis points in the impact period, respectively. Second, the FEVD shows that, 20 quarters ahead, LS shocks explain $11.2 \%$ of the variability of real output growth on average. Third, the HD suggests that the banking system is not just a channel for the main macroeconomic (AD, AS, and MP) shocks, but also contributes significantly to explaining the behavior of real output growth, especially in crisis episodes. During the GFG (2009Q1-2010Q1), LS shocks explained on average a 180-basis point fall in real output growth.

The remainder of the document is as follows. Section 2 describes the methodology used to estimate the BVAR model and the scheme for identifying the sign restrictions. Section 3 discusses the data and the main results. Section 4 concludes and provides policy implications.

\section{Methodology}

This section explains the BVAR model employed in this paper, as well as the identification scheme (based on sign restrictions) used to obtain the IRFs, the FEVD, and the HD.

Bayesian Vector Autoregressive (BVAR) Model

Consider the reduced form of a VAR model of order $\boldsymbol{p}$ :

$$
y_{t}=A_{0}+\sum_{i=1}^{p} A_{i} y_{t-i}+u_{t}
$$

where for $t=1, \ldots, T, y_{t}$ is an $n \times 1$ vector containing the observations for the $n$ endogenous variables of the model; $u_{t}$ is an $n \times 1$ vector of errors such that $u_{t} \sim \operatorname{iid} \mathbb{N}\left(0, \Sigma_{\mathrm{u}}\right) ; A_{0}$ is an $n \times 1$ vector containing the intercepts of the model; $A_{i}=\left[a_{m j}^{i}\right]$ is an $n \times{ }_{n}$ matrix of coefficients, where $m$ and $j$ represent the rows and columns of matrix $A_{\mathrm{i}}$, respectively.

In line with Canova (2011) and Koop and Korobilis (2010), it is possible to write model (1) as follows:

$$
\mathbf{Y}=\mathbf{X A}+\mathbf{U}
$$

where $\mathbf{Y}=\left[\begin{array}{llll}y_{1} & y_{2} & \ldots & y_{T}\end{array}\right]^{\prime}$ and $\mathbf{U}=\left[\begin{array}{llll}u_{1} & u_{2} & \ldots & u_{T}\end{array}\right]^{\prime}$. Additionally, $\mathbf{X}=\left[\begin{array}{llll}x_{1} & x_{2} & \ldots & x_{\mathrm{T}}\end{array}\right]^{\prime}$ is a $T \times K$ matrix, where $x_{t}=\left(1, y_{t-1}^{\prime}, \ldots, y_{t-p}^{\prime}\right)$ and $K=1+n p$ is the number of coefficients in each VAR equation; $\mathbf{A}=\left[\begin{array}{llll}A_{0}^{\prime} & A_{1}^{\prime} & \ldots & A_{p}^{\prime}\end{array}\right]^{\prime}$ is a $K \times n$ matrix containing the coefficients of the model; $\alpha=\operatorname{vec}(\mathbf{A})$ is an $n K \times 1$ vector containing all the coefficients of the model; and $y=\operatorname{vec}(\mathbf{Y})$ is an $n T \times 1$ vector containing the $T$ stacked observations for each endogenous variable in the model. The model (1) can also be written as:

$$
y=\left(I_{n} \otimes \mathbf{X}\right) \alpha+e,
$$

where $e \sim \mathbb{N}\left(\mathbf{0}, \Sigma_{\mathrm{u}} \otimes I_{T}\right)$. Canova (2011) indicates that from the latter expression it is possible to obtain the approximate likelihood function:

$$
L\left(\alpha, \Sigma_{u} \mid y\right) \propto\left|\Sigma_{u} \otimes I_{T}\right|^{-0.5} \exp \left\{-0.5\left(y-\left(I_{n} \otimes \mathbf{X}\right) \alpha\right)^{\prime}\left(\Sigma_{u} \otimes I_{T}\right)^{-1}\left(y-\left(I_{n} \otimes \mathbf{X}\right) \alpha\right)\right\}
$$

This likelihood function may be written as:

$$
\begin{gathered}
L\left(\alpha, \Sigma_{u} \mid y\right) \propto \quad\left|\Sigma_{u}\right|^{-0.5 K} \exp \left\{-0.5(\alpha-\hat{\alpha})^{\prime}\left(\Sigma_{u}^{-1} \otimes \mathbf{X}^{\prime} \mathbf{X}\right)(\alpha-\hat{\alpha})\right\} \\
\times\left|\Sigma_{u}\right|^{-0.5(T-K)} \exp \left\{-0.5 \operatorname{tr}\left[\left(\left(\Sigma_{u}^{-0.5} \otimes I_{T}\right) y-\left(\Sigma_{u}^{-0.5} \otimes \mathbf{X}\right) \hat{\alpha}\right)^{\prime}\right.\right. \\
\left.\left.\left(\left(\Sigma_{u}^{-0.5} \otimes I_{T}\right) y-\left(\Sigma_{u}^{-0.5} \otimes \mathbf{X}\right) \hat{\alpha}\right)\right]\right\}
\end{gathered}
$$


where $\hat{\alpha}=\left(\Sigma_{u}^{-1} \otimes \mathbf{X}^{\prime} \mathbf{X}\right)^{-1}\left(\Sigma_{u}^{-1} \otimes \mathbf{X}\right)^{\prime} y$ represents the Ordinary Least Squares (OLS) estimator of equation (3); i.e., the likelihood is the product of a Normal and a Wishart:

$$
L\left(\alpha, \Sigma_{u} \mid y\right) \propto \mathbb{N}\left(\alpha \mid \hat{\alpha}, \Sigma_{u}, \mathbf{X}, y\right) \times \mathbb{W}\left(\Sigma_{u}^{-1} \mid y, \mathbf{X}, \hat{\alpha}, T-K-n-1\right)
$$

or: $\quad \alpha \mid \Sigma_{u}, y \sim \mathbb{N}\left(\hat{\alpha}, \Sigma_{u} \otimes\left(\mathbf{X}^{\prime} \mathbf{X}\right)^{-1}\right) \quad$ and $\quad \Sigma_{u}^{-1} \mid y \sim \mathbb{W}\left(S^{-1}, T-K-n-1\right), \quad$ where $S=(\mathbf{Y}-\mathbf{X} \widehat{\mathbf{A}})^{\prime}(\mathbf{Y}-\mathbf{X} \widehat{\mathbf{A}})$, with $\widehat{\mathbf{A}}=\left(\mathbf{X}^{\prime} \mathbf{X}\right)^{-1} \mathbf{X}^{\prime} \mathbf{Y}$ as the OLS estimator of model (2).

The Bayesian approach is an appropriate choice to address over-parameterization of VAR models and scarce time series information. Koop and Korobilis (2010) emphasize that the a priori information provided by the Bayesian approach improves estimators through preliminary information denominated shrinkage. This paper performs a Bayesian estimation of a VAR model using a Normal-Inverse-Wishart prior ${ }^{3}$, 1,000 simulations, and one lag, in line with the Schwarz Information Criterion (SIC).

\section{Sign Restrictions}

The reason for performing identification under sign restrictions is that usually short-run restrictions are not based on theoretical considerations (Peersman, 2005); and long-run restrictions may occasionally be inappropriate (Faust and Leeper, 1997). Peersman (2005) stresses that one of the advantages of this kind of identification is that it is not necessary to impose zero restrictions on the matrix of contemporaneous effects or the long-run matrix. At the same time, sign restrictions highlight the underlying economic theory.

Identification under sign restrictions begins by estimating the $\operatorname{VAR}(\mathrm{p})$ model in reduced form, represented by equation (1). This estimation yields the variance-covariance matrix of reduced shocks, denoted by $\hat{\Sigma}_{u}$. Cholesky's decomposition is then performed on this matrix in the following manner: $\hat{\Sigma}_{u}=B B^{\prime}$, such that $B$ is an inferior triangular matrix, where $u_{t}=B \epsilon_{t}$ and $\epsilon_{t}$ is the vector of structural shocks.

Sign identification is not based on a unique decomposition, as it may be performed using an orthogonal matrix ${ }^{4} Q$, such that $Q Q^{\prime}=I$. From this result, the decomposition of the estimated variance-covariance matrix for the reduced shocks may be written as $\hat{\Sigma}_{u}=B B^{\prime}=B I B^{\prime}=B Q Q^{\prime} B^{\prime}=\tilde{B} \tilde{B}^{\prime}$, where $\tilde{B}=B Q$ is not necessarily an inferior triangular matrix. From this new decomposition, $u_{t}=\tilde{B} \epsilon_{t}$ and, therefore, a new set of IRFs results for the structural shocks.

Thus, it is possible to obtain as many $Q$ (and therefore $\widetilde{B}$ ) matrices as desired. Along these lines, the objective of this kind of identification is verifying if the IRFs obtained through matrix $\widetilde{B}$ satisfy a set of sign restrictions typically defined by economic theory. In contrast with a conventional VAR model, under a BVAR model there are different possible simulations for the coefficients. Along these lines, for each simulation for the coefficients of the BVAR model we calculate a matrix $Q$, and therefore a matrix $\widetilde{B}$ to obtain a set of IRFs that comply with the sign restrictions. Thus, we obtain 1,000 sets of IRFs complying the sign restrictions (one set of IRFs per simulation).

3 We are using a Normal-Inverse-Wishart conjugate prior which is actually a Minnesota-type prior. As Kadilayala and Karlsson (1997) suggest, this prior retains the principles of the Minnesota prior of Litterman (1986). On the other hand, as mentioned by Bańbura et al. (2008), the Normal-Inverse-Wishart prior is an improvement over the original proposal of the Minnesota prior of Litterman_(1986). The improvement allows to solve/make more flexible the problems originated by the assumption of a fixed variance-covariance matrix used in the Minnesota prior. Furthermore, following the recommendation of Koop and Korobilis (2010), we set the value of zero for the priors of the means of the autoregressive coefficients since we have verified/shown that all our variables used in the BVAR are stationary; see footnote 6 .

4 This orthogonal matrix $Q$ is originated by the $\mathrm{QR}$ decomposition of a random matrix, in turn obtained from a multivariate standard Normal distribution. 
This paper uses sign restrictions to identify LS, AD, AS, and MP shocks. Paustian (2007), Hristov et al. (2012), and Gambetti and Musso (2017) note that identifying more shocks may contribute to obtaining the right IRFs: if two or more shocks cause similar effects, it might not be possible to distinguish one set from others. Therefore, it is better to identify as many structural shocks as possible, as long as they find support in economic theory. Along these lines, this paper suggests four identification schemes. This section details the first one (baseline scheme), while the other three (alternative schemes) are used and described in the section about the robustness analysis. The baseline scheme shown in Table 1 is in line with the restrictions proposed by Hristov et al. (2012).

Table 1. Sign Restrictions (Baseline Identification)

\begin{tabular}{lccccc}
\hline Shock & $\begin{array}{c}\text { Real GDP } \\
\text { Growth }\end{array}$ & Inflation & $\begin{array}{c}\text { Money Market } \\
\text { Rate }\end{array}$ & $\begin{array}{c}\text { Loan Volume } \\
\text { Growth }\end{array}$ & Loan \\
\hline AD & $(-)$ & $(-)$ & $(-)$ & $(?)$ & $(-)$ \\
AS & $(-)$ & $(+)$ & $(+)$ & $(?)$ & $(?)$ \\
MP & $(-)$ & $(-)$ & $(+)$ & $(?)$ & $(+)$ \\
LS & $(-)$ & $(?)$ & $(-)$ & $(-)$ & $(+)$ \\
\hline
\end{tabular}

AD: Aggregate Demand, AS: Aggregate Supply, MP: Monetary Policy, LS: Loan Supply.

First, a contractionary AS shock is interpreted as an increase in inflation. This may be represented as a production cost shock. In this scenario, Peersman and Straub (2006) and Canova and Paustian (2011) argue that such a shock reduces output: as the central bank emphasizes inflation control, it raises the short-run interest rate. Additionally, the responses of loan market variables are not restricted, implying that the data determine the signs of these responses.

Second, a contractionary MP shock is interpreted as an unexpected increase in the short-run interest rate ${ }^{5}$ by the monetary authority. Peersman and Straub (2006) and Canova and Paustian (2011) indicate that such a contractionary MP measure causes a fall in output, and therefore in inflation. Moreover, as bank rates are linked to the interbank rate, the bank lending rate rises. De Bond (2005) mentions that there is abundant literature about the effective pass-through effect from the policy rate to lending rates. The restrictions imposed on output and inflation are in line with the suggestions by Pérez-Forero and Vega (2014) for assessing the impact of monetary policy on Peru's economy.

Third, in the case of a contractionary AD shock, output and inflation move in the same direction; i.e., both decrease. In line with standard economic theory, the monetary authority reacts by reducing the short-run interest rate. While these restrictions suffice to distinguish AD shocks from AS and MP shocks, they are insufficient to distinguish them from LS shocks. In line with Hristov et al. (2012), lending rates also decrease. They indicate that this restriction is explained by the negative impact of a fall in output on the demand for bank loans and by how the latter decreased lending rates. In turn, the latter restriction may be founded on the effectiveness of the pass-through from the policy rate to lending rates, as suggested by De Bond (2005).

Finally, Atta-Mensah and Dib (2008), Gertler and Karadi (2011), Gilchrist et al. (2009), Cúrdia and Woodford (2010), and Gerali et al. (2010) argue that adverse LS shocks cause a fall in loans and output, as well as an increase in lending rates. In light of the lack of consensus about the response of inflation, no restriction is imposed on this variable. However, Hristov et al. (2012)

5 This rate will be denominated "money market rate" in all Tables and Figures. 
emphasize that the restrictions considered do not suffice to distinguish an LS shock from an adverse AS shock or a contractionary MP shock. Therefore, in order to differentiate the LS shocks despite a lack of consensus, a restriction is imposed on the MP rate. Given that AS and MP shocks consider an increase in the MP rate, the identification scheme used in this paper considers an MP rate cut in the face of an adverse LS shock. All restrictions are applied to the first two quarters.

\section{The Median Model}

It is a common practice when using BVAR models with sign restrictions to report the IRF mean or the median obtained from each coefficient simulation. However, Fry and Pagan (2011) highlight an interpretation problem in reporting the median as a summary statistic for the IRFs. They indicate that the IRF median results from different models or simulations for each time horizon. In this light, this paper follows Hristov et al. (2012) in calculating the median model; i.e., the model produced by the IRF group that is closest to the median for the IRFs. Hristov et al. (2012) note that this model is obtained by minimizing a measure of the distance between the IRFs in each simulation and the median for the IRFs. Like Hristov et al. (2012), the minimization is carried out using as measure of the distance the sum of the square difference between the IRF for a simulation and the median for the IRFs over a horizon of 20 quarters ahead. In the remainder of this paper, the calculations for the IRFs, the FEVD and the HD result from the median model.

\section{Empirical Evidence}

This section describes the data used in the estimation and analyzes the results. First, Peru's economic context is described using the variables used and the period considered. Second, it shows the main results of the baseline scheme for identifying structural shocks (IRFs, FEVD, and HD). Lastly, we perform a robustness analysis for the IRFs generated by an LS shock, with two variants. The first one consists of three alternative sign restriction schemes for the same variables in the model; and the second one is maintaining the baseline identification scheme, but substituting real non-primary GDP growth for real GDP growth.

\section{The Data}

This paper uses available BCRP information for 1996Q1-2017Q4. The beginning of the sample is determined by banking system variables. While there is information on credit volume since 1992, data for the interest rate on those loans is only available since 1996. The variables considered are real annual GDP growth, annual inflation, the interbank rate, the lending rate in domestic currency (tasa activa en moneda nacional, TAMN), annual domestic-currency bank credit growth, and annual export price index growth. Inclusion of the latter is justified by the need of a variable that controls or captures the effect of external shocks on Peru's economy ${ }^{6}$.

Over the last 20 years, annual average growth in Peru has been 4.5\% (even considering the 1998 and 2008-2009 crises) mainly due to a favorable external environment and positive developments in the financial system (especially in the banking industry).

6 The series used in the estimates are expressed in annual growth rates (in percentages) except for the two interest rates. Certainly most of them show strong dependence; however, all of them are stationary $(\mathrm{I}(0))$. Using a standard ADF statistic where the lag selection has been selected using the 5\% t-sig method (see $\mathrm{Ng}$ and Perron (1995)), the results are: -2.69 (c) for real GDP growth, -4.13(a) for annual inflation, -6.73(a) for money market rate, -2.57(c) for loan volume growth, -2.86(b) for loan rate and -2.64(c) for export prices growth where the letter in parentheses indicates the level of rejection $(\mathrm{a}=1 \%, \mathrm{~b}=5 \%, \mathrm{c}=10 \%)$. We have also used the BIC (SIC) criterion to select lag length and we have obtained stronger rejections $(1 \%$ or $2.5 \%)$ in all variables. It is well known in the literature -see $\mathrm{Ng}$ and Perron $(1995,2001)$ - that the BIC selects very short lags which might not control the strong dependence found in our variables. Therefore, we prefer to use the $5 \%$ t-sig criterion because we can choose a number of lags greater than the one selected by BIC and that allows us to control the strong correlation but not select a number of lags so high that the power of the statistic decreases. 
Panel (a) in Figure 1 shows that annual GDP growth and domestic-denominated bank credit growth had a similar behavior during the period of analysis, although more so since 2005. Panel (b) shows a clear positive relationship between domestic-denominated bank credit and GDP growth. Panel (c) identifies two distinctive moments in the interest rate series. First, interest rate behavior is irregular, especially at the end of the 1990s, in the context of the Asian (1997) and Russian (1998) crises. In this first moment, the TAMN was above 25\%, a considerable cost for bank loans. However, the behavior of the interbank interest rate changed markedly when the BCRP adopted an inflation targeting (IT) regime in 2002. In the second half of 2003, the BCRP began to use the reference interest rate as policy instrument, in a context where credit costs fell below $25 \%$ (to close to $15 \%$ in the final years) and interbank rate volatility declined considerably.

Figure 1. Panel (a): Real GDP Growth and Loan Volume Growth (in percentage). Panel (b): Relation between Real GDP Growth and Loan Volume Growth. Panel (c): Interest Rates (in percentage). Panel (d): Inflation (annual percentage change of CPI). Panel (e): Export Price Growth. Panel (f): Real GDP Growth and Export Price Growth (in percentage).
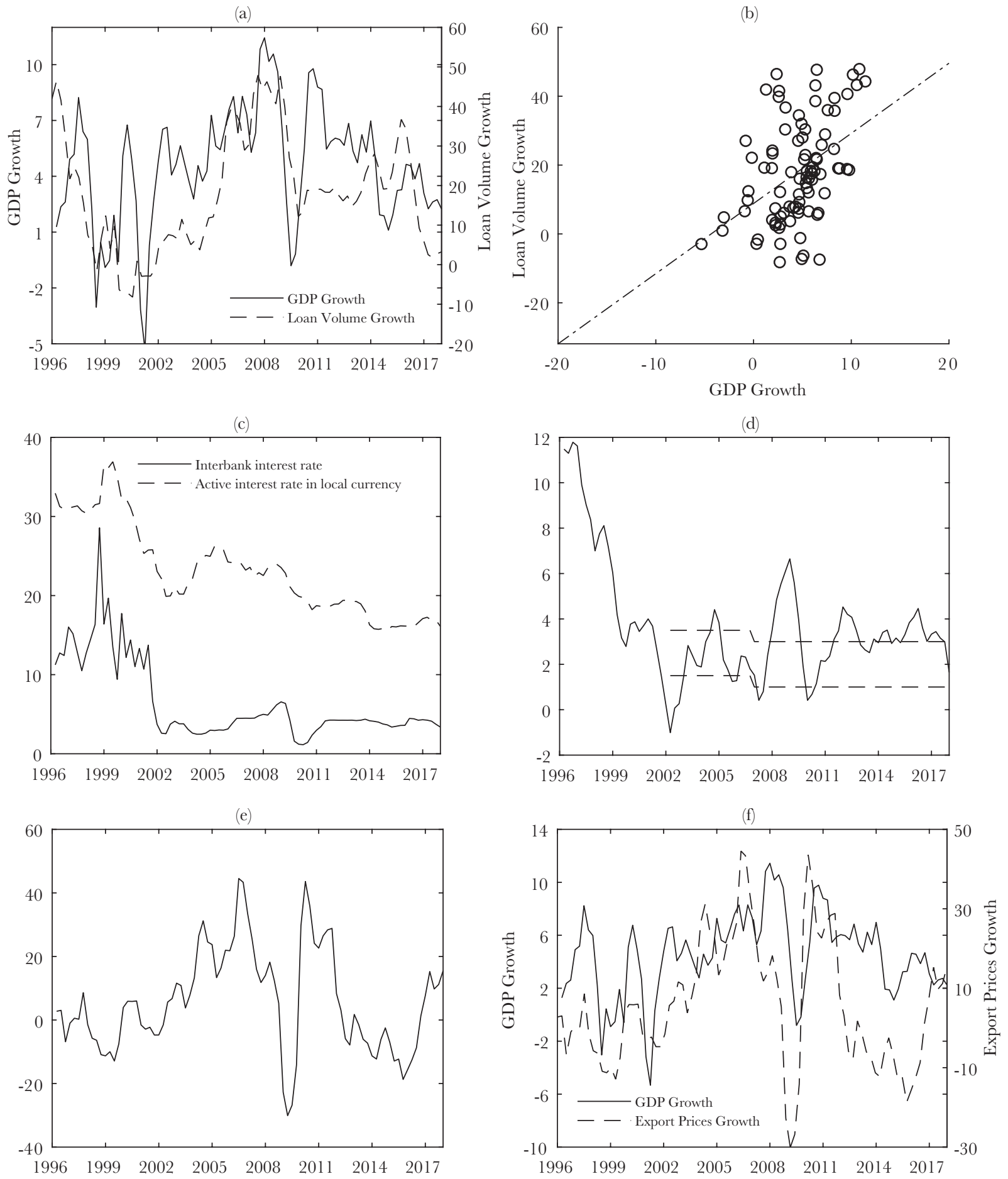
Especially, inflation behavior changed under the IT regime. Panel (d) shows that inflation converges to the IT target band since 2002. In general, inflation has remained within the band since then, except under the GFG (2008-2009). The solid and dotted lines represent annual inflation and the IT band, respectively.

Export price index growth is included to capture external shocks (Panel (e)). Panel (f) shows that when the export price index increases, real GDP rises, like from 2003 to the beginning of 2008. However, when it falls, as during the GFC or from end-2010 to end-2016, the economy decelerates.

\section{Impulse Response Functions: LS Shocks}

Figure 2 shows the response of GDP growth, inflation, the interbank interest rate, domestic-currency credit growth, the TAMN, and the credit spread to an adverse LS shock. The credit spread is calculated as the difference between the response of the TAMN and the interbank interest rate; and can be interpreted as banks' net gain on each loan. In particular, the dotted lines represent the IRF medians for the Bayesian estimation with one thousand draws; and the solid lines represent the IRFs obtained from the median model. The edges of the shadowed area represent the 16th and 84th percentiles of the IRFs obtained from the one thousand draws. The IRF horizon considers 20 quarters.

Figure 2. IRFs: Loan Supply Shock. (Baseline Identification). The dashed lines represent the median of IRFs calculated from BVAR estimation with 1,000 draws that satisfy the sign restrictions, while the solid lines represent the median model. The boundaries of shaded areas represent 16 and 84 percentiles.
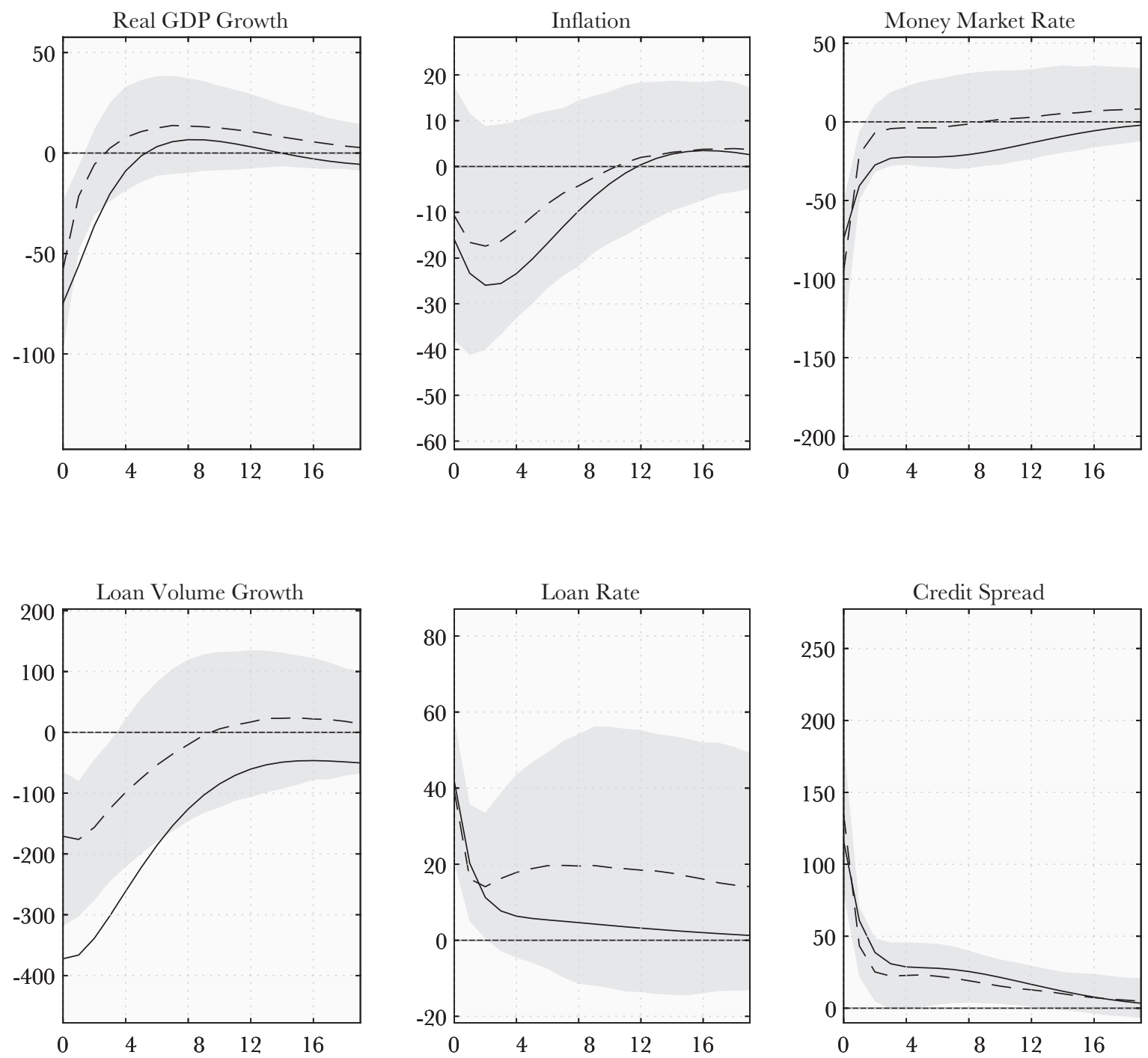
Regarding the bank market rate, an adverse LS shock causes a 372- and 366-basis point contraction in domestic-currency credit during the first two quarters, in tandem with a 42- and 20-basis point increase in the TAMN during the first two quarters. Over the next quarters, the adverse effect on both variables dissipates and converges to zero. Although within the 20 quarters considered the IRF for credit growth does not fall to zero, the latter value is considered within the probability interval starting the fourth quarter.

In the real sector, an adverse LS shock reduces real output growth. In particular, such a shock causes a 75-, 56-, 36-, and 20-basis point contraction in output growth during the first four quarters, respectively. Although from the third quarter the value zero is part of the probability interval, it is only from the seventh quarter that an increase in real output growth takes place. The behavior of output during the first quarters is explained by a contraction in the pace of growth of domestic-currency credit and the increase in loan costs. These effects create an adverse environment for financing production activities. However, this behavior is offset by the workings of monetary policy; i.e., the adverse impact on real GDP growth dissipates in the first year and a half, moving to positive territory from the seventh quarter.

While the zero value is included in the probability interval for inflation during the 20 quarters, the adverse LS shock causes, through a contraction in output growth, a fall in inflation during the first 12 quarters, although never above 30 basis points. In this context, the BCRP adopted an expansionary stance through a 74- and 40-basis point reduction during the first two quarters. As inflation was largely unaffected by the LS shock and output was taking long to recover, the monetary authority adopted an expansionary stance during the first two quarters. The BCRP's stance became less expansionary from the third quarter.

As a result of the increase in the TAMN (caused by the LS shock) and the expansionary response through the interbank rate, during the first two quarters the credit spread increased by 116 and 60 basis points, respectively; i.e., while the adverse LS shock decelerated credit growth, banks' profit margin per loan increased. This considerable increase in the credit spread decreased over time and the impact of the LS shock on the TAMN dissipated because of the monetary policy response.

In sum, an adverse LS shock has a negative impact on the bank loan market and the real sector. The shock causes a contraction in credit and real GDP growth and increases bank lending rates. GDP growths at a slower pace despite the expansionary reduction of the interbank interest rate. This result provides evidence of the importance of bank loans for GDP growth.

\section{Forecast Error Variance Decomposition}

The FEVD serves to assess the quantitative importance of structural shocks. Table 2 shows the annual average FEVD of the median model for each variable in response to the four shocks identified in this paper. The same number of quarters as for the IRFs is considered. The sum of the four shocks indicates that a considerable part of the variability of endogenous variables can be explained using this identification scheme.

Table 2 shows that the four structural shocks explain 45\%-90\% of the variation in endogenous variables. Additionally, credit growth is the variable whose variance is explained to the largest extent by the identified shocks (around $89.8 \%$ on average), while the lending rate is the variable whose variance is explained to the least extent (around $48.4 \%$ on average).

$\mathrm{AD}$ and AS shocks explain around $68.1 \%$ of the variance of GDP growth $(44.4 \%$ and $23.7 \%$, respectively). Additionally, the LS shock explains $11.2 \%$ of the variability of GDP growth on average, with a maximum $(16.0 \%)$ and minimum $(8.7 \%)$ participation in the first and fifth year, respectively. The relatively high participation of the LS shock, while lower than for the $\mathrm{AD}$ and $\mathrm{AS}$ shocks, is slightly higher than for the MP shock ( $6.6 \%$ on average). 
Table 2. Forecast Error Variance Decomposition (Baseline Identification) (in percentages)

\begin{tabular}{|c|c|c|c|c|c|c|}
\hline & \multirow{3}{*}{ Year } & \multirow[t]{2}{*}{$\mathrm{AD}$} & \multirow[t]{2}{*}{ AS } & \multirow[t]{2}{*}{ MP } & \multirow[t]{2}{*}{ LS } & \multirow[t]{2}{*}{ Sum of } \\
\hline & & & & & & \\
\hline & & Shock & Shock & Shock & Shock & Shocks \\
\hline Real GDP & 1 st & 64.0 & 8.6 & 2.4 & 16.0 & 91.0 \\
\hline \multirow[t]{4}{*}{ Growth } & 2nd & 45.4 & 24.4 & 4.6 & 12.5 & 86.9 \\
\hline & 3rd & 39.5 & 29.5 & 7.8 & 9.8 & 86.6 \\
\hline & 4 th & 37.1 & 28.4 & 9.1 & 9.0 & 83.6 \\
\hline & 5 th & 36.0 & 27.7 & 9.3 & 8.7 & 81.7 \\
\hline Annual & $1 \mathrm{st}$ & 7.3 & 40.0 & 5.6 & 7.0 & 59.9 \\
\hline \multirow[t]{4}{*}{ Inflation } & 2nd & 9.1 & 26.5 & 5.4 & 9.9 & 50.9 \\
\hline & 3rd & 7.3 & 23.8 & 4.4 & 8.6 & 44.1 \\
\hline & 4 th & 7.6 & 27.4 & 5.6 & 7.3 & 47.9 \\
\hline & 5 th & 8.3 & 29.0 & 7.6 & 6.7 & 51.6 \\
\hline Money Market & $1 \mathrm{st}$ & 5.3 & 46.2 & 25.1 & 8.3 & 84.9 \\
\hline \multirow[t]{4}{*}{ Rate } & 2nd & 6.2 & 44.9 & 28.0 & 7.6 & 86.7 \\
\hline & $3 \mathrm{rd}$ & 6.8 & 40.9 & 26.8 & 7.6 & 82.1 \\
\hline & 4 th & 6.5 & 37.0 & 26.4 & 7.3 & 77.2 \\
\hline & 5 th & 6.0 & 34.9 & 26.9 & 6.9 & 74.7 \\
\hline Loan Volume & 1st & 6.4 & 20.5 & 7.4 & 48.7 & 83.0 \\
\hline \multirow[t]{4}{*}{ Growth } & 2nd & 9.6 & 36.1 & 11.4 & 32.1 & 89.2 \\
\hline & $3 \mathrm{rd}$ & 13.0 & 43.7 & 15.5 & 20.4 & 92.6 \\
\hline & 4 th & 14.5 & 43.9 & 18.6 & 15.8 & 92.8 \\
\hline & 5 th & 14.6 & 42.0 & 20.5 & 14.1 & 91.2 \\
\hline \multirow[t]{5}{*}{ Loan Rate } & 1 st & 20.4 & 7.8 & 20.7 & 12.0 & 60.9 \\
\hline & 2nd & 16.0 & 5.8 & 22.5 & 4.3 & 48.6 \\
\hline & $3 \mathrm{rd}$ & 13.1 & 5.2 & 23.7 & 3.1 & 45.1 \\
\hline & 4 th & 11.7 & 4.7 & 24.9 & 2.6 & 43.9 \\
\hline & 5 th & 10.9 & 4.4 & 26.0 & 2.4 & 43.7 \\
\hline
\end{tabular}

AD: Aggregate Demand, AS: Aggregate Supply, MP: Monetary Policy, LS: Loan Supply.

The LS shock explains around $26.2 \%$ in the case of domestic-currency bank credit over the five years, with a participation of $48.7 \%$ and $32.1 \%$ in the first and second year, respectively. In the following years, AS and MP shocks gain greater participation in the variability of bank loans. This result is explained by the effectiveness of monetary policy. The BCRP responds mainly to shocks (like AS shocks) affecting inflation directly by affecting the bank loan market as an intermediate step in the monetary transmission mechanism. Therefore, AS and MP shocks have a significant participation in the variability of bank loans.

$\mathrm{MP}$ and $\mathrm{AD}$ shocks together explain around $38.0 \%$ on average $(23.6 \%$ and $14.4 \%$, respectively) in the case of the interest rate on bank loans. The high participation of the MP shock is explained by the monetary transmission mechanism. An important element of the latter is the 
pass-through from the interbank interest rate to bank lending rates. Therefore, it is reasonable to expect a considerable part of the variability of the interest rate on bank loans to be explained by interbank rate movements. An interesting result is that the participation of an MP shock is relatively high in the FEVD of the interest rate on bank loans, but rather low in the FEVD of credit growth. This provides evidence that the bank loan market adjusts largely via prices (credit cost) rather than quantities.

In sum, the four shocks (AD, AS, MP, and LS) explain a significant part of the behavior of the variables used in this paper. In particular, while the variability of GDP growth is explained mainly by AD and AS shocks, LS shocks have an important participation, even higher than MP shocks, in the case of GDP growth. Additionally, the behavior of inflation and the interbank interest rate is explained mostly by AS shocks, while bank market variables (credit growth and the TAMN) are largely explained by LS and MP shocks, respectively.

\section{Historical Decomposition}

HD allows a more accurate analysis of specific points in the sample. This sub-section assesses the evolution of LS shocks and their contribution to domestic-currency credit and real GDP growth. To this end, HD is performed for the two variables of interest, taking into consideration the median model.

\section{Evolution of LS shocks}

Panel (a) in Figure 3 shows the evolution of LS shocks estimated for the entire period. A positive (negative) value stands for an expansionary (contractionary) shock. Three contractionary LS shock phases may be identified in the period of analysis. Each phase has a duration of at least three consecutive quarters and a negative average contribution to real GDP growth of at least 150 basis points.

The first period covers the end of the 1990s, when domestic-currency loans were seriously affected by the Asian (1997) and Russian (1998) crises. During the second period (2003-2005), many commercial banks went broke or liquidated their portfolios because of the crises of the end-1990s and the 2001 political crisis. Information from Peru's Bank Association (ASBANG) indicates that the number of banks decreased from 30 to 12 between the 1990s and the 2000s. The third period covers the post-GFG years. Panel (a) in Figure 4 shows an adverse LS shock from the first quarter of 2009 to the first quarter of 2010. Domestic-currency credit growth decreased from 39.8\% in 2009Q1 to $13.3 \%$ in 2010Q1. Therefore, contractionary LS shocks had a considerable impact on Peru's loan market over the last 20 years.

\section{Contribution to Credit Volume and Real GDP Growth}

Panels (b) and (c) in Figures 3 and 4 show observed and counter-factual credit and real GDP growth for the whole sample and during the GFC, respectively. In both cases, the solid and dotted lines represent the observed and counter-factual growth rates, respectively. In particular, observed growth rates contain all estimated shocks (the four discussed above and two that remain unidentified) and their mean within the period of analysis, with the purpose of accurately describing the behavior of the series ${ }^{7}$. Additionally, a counter-factual growth rate is one that would have resulted from a zero LS shock.

In the first period, credit growth would have been higher had the adverse LS shock not taken place. In particular, in absence of the adverse shock, bank loans would have increased $36.7 \%$ instead of $24.8 \%$ on average in 1999Q2-2000Q1. GDP growth shows a similar behavior over the

7 The HD provides an approximation of each series after extracting its deterministic components. In this regard, in adding the mean we seek to approach the behavior of each series in the most accurate manner. 
same period. In absence of the LS shock, output would have increased 7.1\% instead of $5.2 \%$ on average. These results are explained by the Asian (1997) and Russian (1998) crises, which heavily deteriorated the value and quality of bank portfolios.

Figure 3. HD: Loan Supply Shocks in all the sample. Panel (a): Evolution of estimated Loan Supply Shocks in all the sample. Panel (b): Actual and Conterfactual Loan Volume Growth in all the sample. Panel (c): Actual and Conterfactual Real GDP Growth in all the sample. The solid lines represent the actual value of the series while the dashed lines represent the conterfactual value of the series.
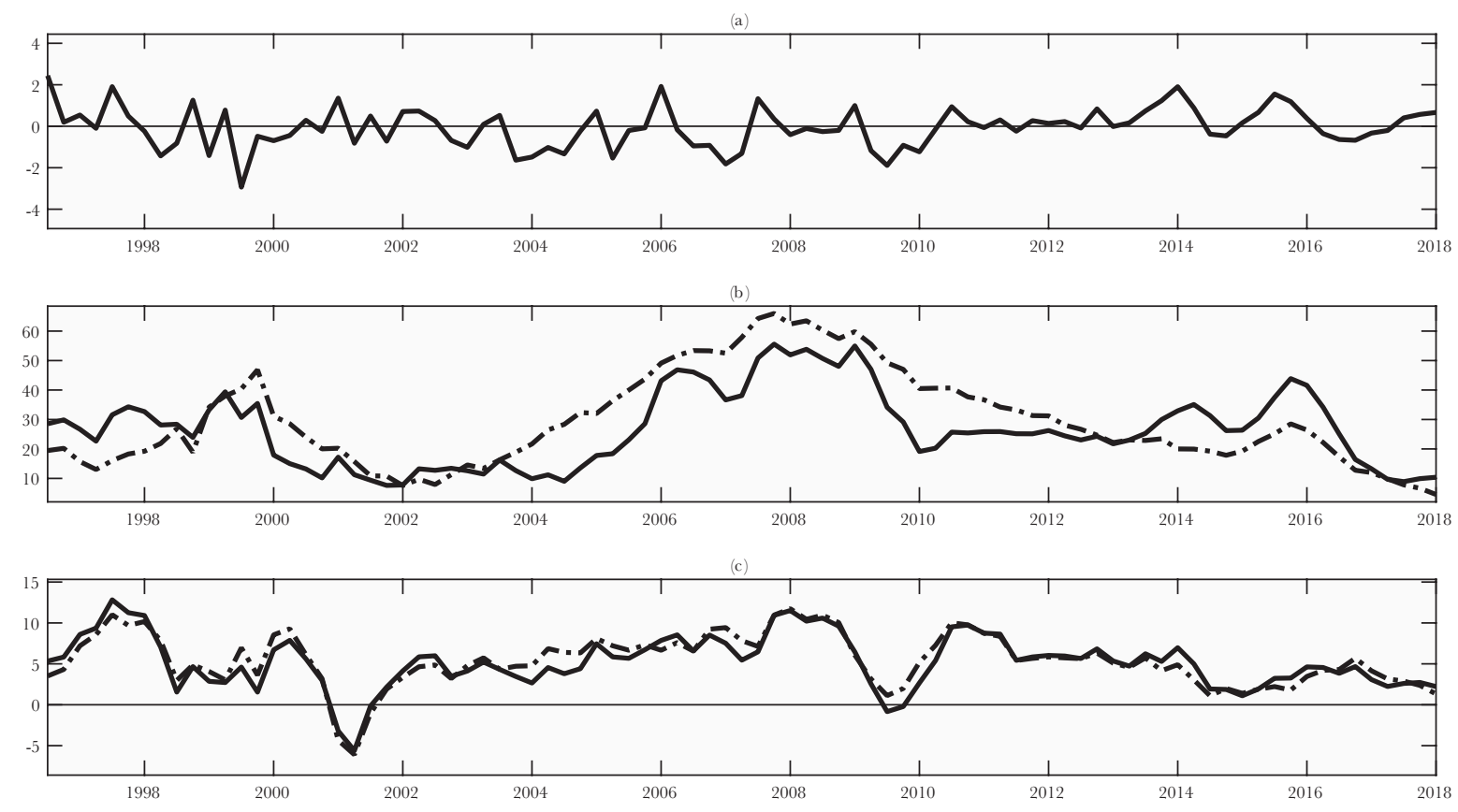

In the years prior to the second adverse LS shock, several banks that had survived by slowly obtaining payment for their loan portfolios finally went broke. In this context, domestic-currency credit growth decelerated in 2003 and 2004 for three main reasons: a substitution effect in the market for financing, non-performing loan write-offs, and greater competition from other financial intermediaries (municipal savings banks and financial entities specialized in micro-finance and consumption). Summarizing, on average bank loans and real GDP would have increased $25.6 \%$ and $5.8 \%$ instead of $11.3 \%$ and $3.8 \%$, respectively, in 2003Q3-2004Q3.

The third LS shock period covers the post-GFC years. HD results indicate that the LS shock had a negative impact on credit and real GDP growth (panels (a) and (b), respectively, in Figure 5). Particularly, in this period real GDP grew $1.9 \%$ on average, compared with $3.7 \%$ in absence of the LS shock. Domestic-currency credit grew $29.9 \%$ on average, compared with $46.6 \%$ in absence of the LS shock. 
Figure 4. HD: Loan Supply Shocks during the crisis. Panel (a): Evolution of estimated Loan Supply Shocks during the crisis. Panel (b): Actual and Conterfactual Loan Volume Growth during the crisis. Panel (c): Actual and Conterfactual Real GDP Growth during the crisis. The solid lines represent the actual value of the series while the dashed lines represent the conterfactual value of the series.

(a)

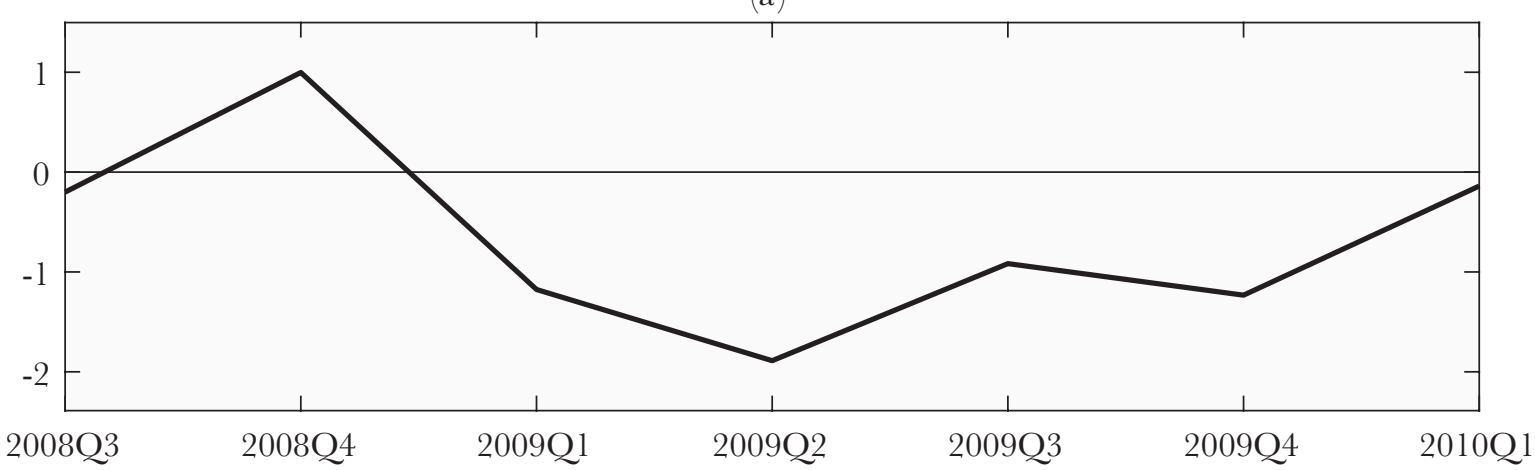

(b)

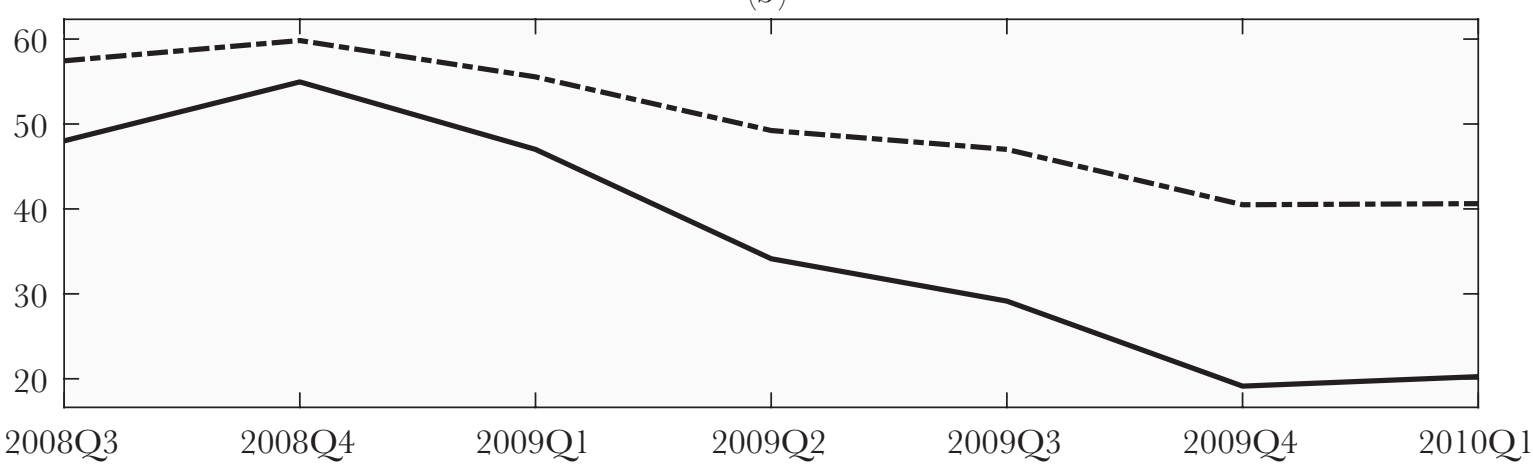

(c)

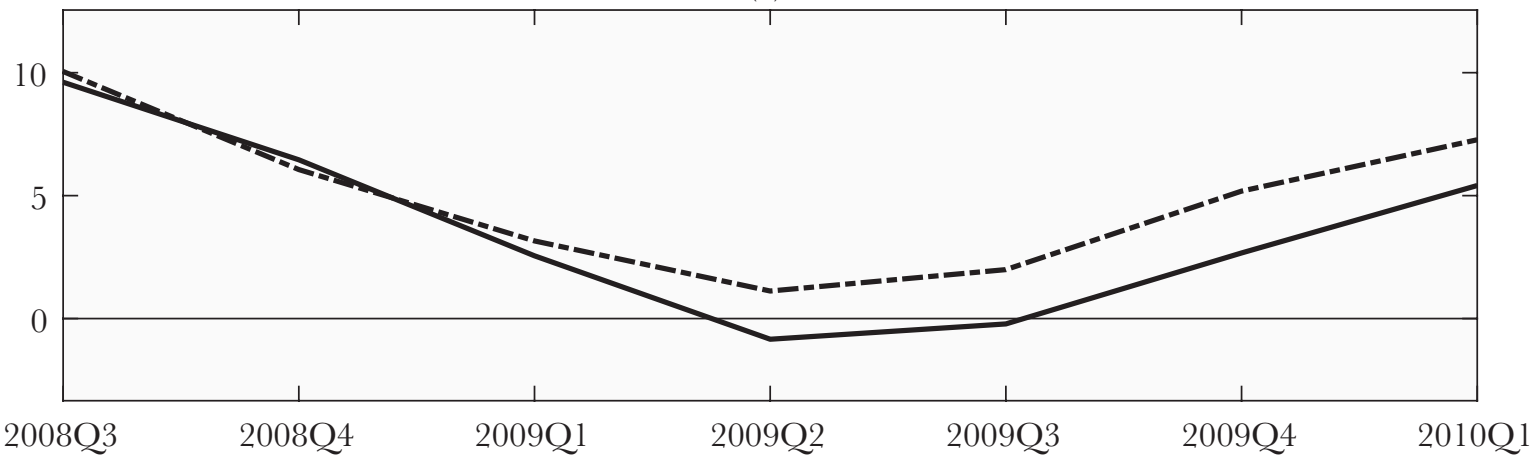

Additionally, it is possible to identify five positive LS shock periods (lasting at least three consecutive quarters): 2001Q4-2002Q2, 2011Q3-2012Q1, 2013Q1-2014Q1, 2014Q4-2015Q4, and 2017Q2-2017Q4. However, the average contribution of these shocks to real GDP growth is much more moderate. The maximum contribution (116 basis points) took place in 2013Q12014Q1, when real GDP grew 5.6\% on average, compared with $4.5 \%$ in absence of the shock.

Summarizing, the analysis shows that the banking system is not just an intermediate step for transmitting the main shocks from macroeconomic fluctuations (AD, AS, and MP shocks). Even under the crises originated outside the economy, the banking system's contribution to the reduction in economic activity has been substantial; i.e., domestic-currency bank loans explain a significant part of output fluctuations. Moreover, within the model and identification scheme explained in this paper, adverse LS shocks have a more relevant contribution than positive ones. 
Figure 5. Contribution of Loan Supply Shock during the crisis. Panel (a): Contribution to Loan Volume Growth. Panel (b): Contribution to Real GDP Growth.
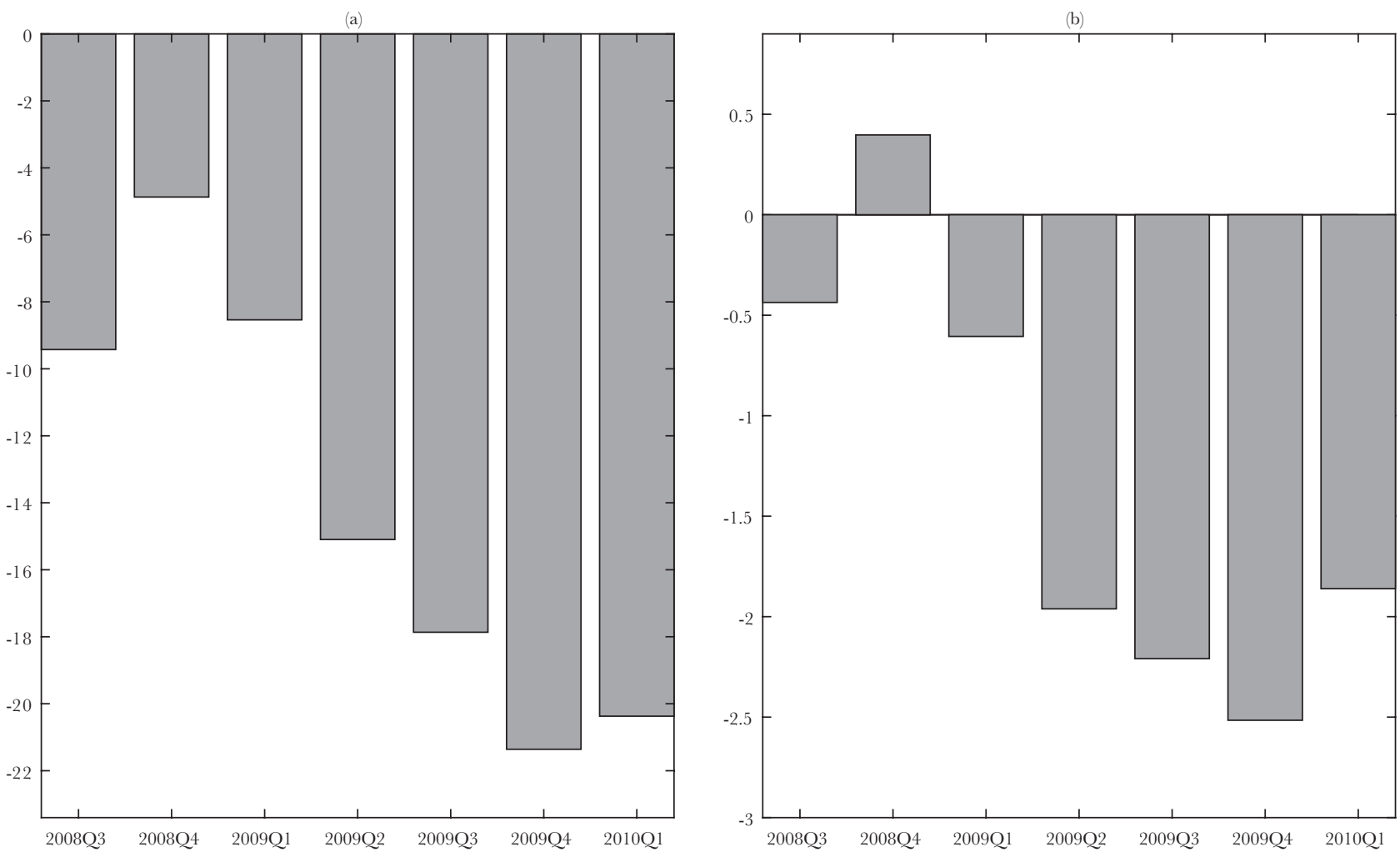

\section{Sensitivity Analysis}

The robustness of the IRF results is tested by estimating a series of alternative models. First, three alternative identification schemes with the same variables are proposed. Second, non-primary real GDP growth instead of total real GDP growth, maintaining the baseline identification scheme.

\section{Robustness to Alternative Identification Schemes}

The first alternative identification scheme is in line with the adaptation derived from the model proposed by Dancourt (2012). This alternative scheme differs from the baseline scheme in that it restricts the response of inflation to the LS shock and of the credit volume to the MP shock, while the response of the interbank interest rate to the AS shock is left free (Table 3, Panel A). The second alternative identification scheme has the same restrictions as the baseline scheme, with a difference: the response of the interbank interest rate is unrestricted in the case of an LS shock. In this adaptation, the response of inflation is unrestricted and, given that the policy interest rate responds to inflation, the data are allowed to yield the IRFs that may result therefrom (Table 3, Panel B). Finally, the third alternative identification scheme, proposed by Hristov et al. (2012) to carry out a sensitivity analysis of the results, leaves the TAMN response unrestricted in the face of an AD shock ${ }^{8}$ (Table 3, Panel G). The authors indicate that, actually, the TAMN response cannot be clear because, on one hand, the fall in economic activity discourages investment opportunities and reduces the demand for loans and lending rates. However, on the other hand, following the financial accelerator mechanism proposed by Bernanke et al. (1999), lower economic activity also reduces borrowers' wealth; and, as a lower collateral causes greater risk, financing costs rise.

8 The authors indicate that this response is identified in the baseline scheme to make sure that AD shocks are differentiated from LS shocks. 
Table 3. Sign Restrictions (Alternative Identification Schemes)

Panel A: Alternative Identification \#1

\begin{tabular}{lccccc}
\hline Shock & Real GDP & CPI & Money Market Rate & Loan Volume & Loan Rate \\
\hline AD & $(-)$ & $(-)$ & $(-)$ & $(?)$ & $(-)$ \\
AS & $(-)$ & $(+)$ & $(?)$ & $(?)$ & $(?)$ \\
MP & $(-)$ & $(-)$ & $(+)$ & $(-)$ & $(+)$ \\
LS & $(-)$ & $(-)$ & $(-)$ & $(-)$ & $(+)$ \\
\hline \multicolumn{7}{c}{ Panel B: Alternative Identification \#2 } \\
\hline Shock & Real GDP & CPI & Money Market Rate & Loan Volume & Loan Rate \\
\hline AD & $(-)$ & $(-)$ & $(-)$ & $(?)$ & $(-)$ \\
AS & $(-)$ & $(+)$ & $(+)$ & $(?)$ & $(?)$ \\
MP & $(-)$ & $(-)$ & $(+)$ & $(?)$ & $(+)$ \\
LS & $(-)$ & $(?)$ & $(?)$ & $(-)$ & $(+)$ \\
\hline \multicolumn{7}{c}{ Panel C: Alternative Identification \#3 } & \\
\hline Shock & Real GDP & CPI & Money Market Rate & Loan Volume & Loan Rate \\
\hline AD & $(-)$ & $(-)$ & $(-)$ & $(?)$ & $(?)$ \\
AS & $(-)$ & $(+)$ & $(+)$ & $(?)$ & $(?)$ \\
MP & $(-)$ & $(-)$ & $(+)$ & $(?)$ & $(+)$ \\
LS & $(-)$ & $(?)$ & $(-)$ & $(-)$ & $(+)$ \\
\hline
\end{tabular}

AD: Aggregate Demand, AS: Aggregate Supply, MP: Monetary Policy, LS: Loan Supply.

Figure 6. IRFs: Loan Supply Shock (Alternative Identifications).
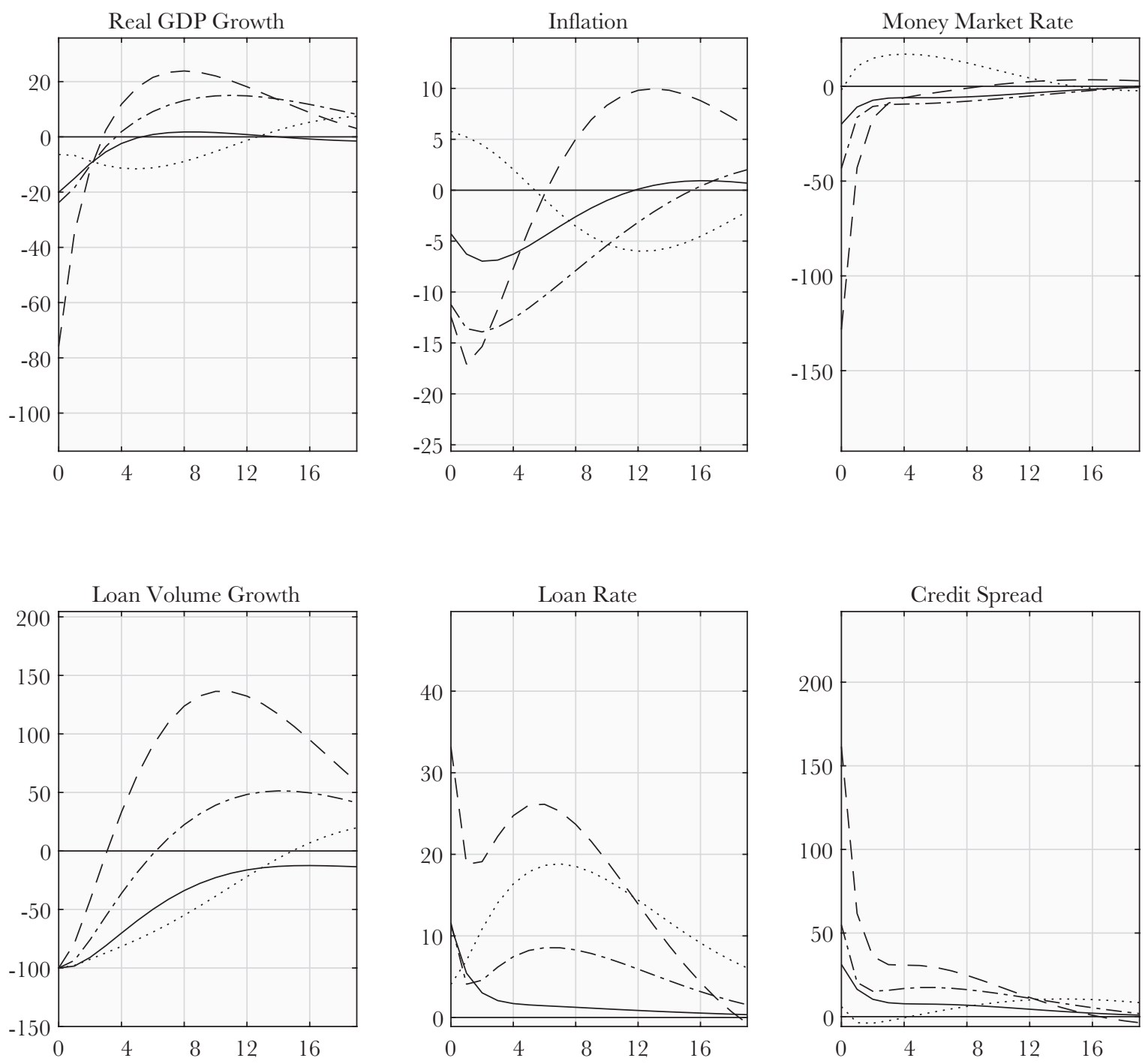
Figure 6 shows the IRFs of the variables of interest to an LS shock under the baseline scheme and the three alternative identification schemes. The solid line represents the IRF for the baseline case; the dashed line represents the IRF for alternative scheme 1; the dotted line represents the IRF for alternative scheme 2; and the dash-dot line represents the IRF for alternative scheme 3.

To compare the baseline and alternative schemes, the IRFs in Figure 6 are normalized to an adverse 100-basis point shock on credit growth. The normalized LS shock shows a more protracted adverse effect under the baseline scheme and alternative scheme 2. In contrast, alternative schemes 1 and 3 show a recovery in bank credit growth starting the third and fifth quarters, respectively.

Additionally, the adverse LS shock rises the cost of bank loans. The lowest increase occurs under alternative scheme 2 ( 4 basis points) and the baseline scheme (11 basis points). The highest increase occurs under alternative schemes 1 and 3 (33 and 12 basis points, respectively).

The behavior of the rate on bank loans in the impact period explains the response of real GDP growth to the adverse LS shock. While output fall under all four identification schemes, it is highest under alternative schemes 1 and 3 (76 and 24 basis points, respectively), associated with the higher increase in credit cost; and lowest under alternative scheme 2 and the baseline scheme (6 and 20 basis points, respectively), associated with the lower increase in credit cost.

The impact on inflation is inconclusive, as the adverse LS shock causes different responses under the identification schemes considered ${ }^{9}$. Inflation decreases under alternative schemes 1 and 3 and the baseline scheme (in line with the response of output), and increases under alternative scheme 2 (in line with the higher cost to companies caused by higher financing costs).

The response of the policy rate for the identification schemes is in line with the responses of output and inflation. First, under the baseline scheme and alternative schemes 1 and 3, the monetary authority decides to reduce the interest rate so that real GDP growth and inflation can recover from the contractionary impact of an adverse LS shock. Second, under alternative scheme2, the BCRP is more concerned with the increase in inflation than with lower GDP growth; i.e., under this scheme, the interbank rate increases to reduce inflation at the expense of lower real GDP growth (although by no more than 20 basis points).

Summarizing, the IRFs obtained through the alternative identification schemes provide robustness to the results for the impact of an adverse LS shock on the variables of interest, mainly real GDP growth. The variable with a different behavior is inflation. While the result for this variable is linked to the behavior of the policy interest rate, it does not affect significantly the effect on output growth (one of the main goals of this paper).

\section{Analysis of Non-Primary GDP}

It is useful to consider non-primary real GDP growth instead of total real GDP growth, as the stylized facts about Peru's economy show that financing of the non-primary sector is more linked to banks, while the primary sector is more linked to the capital market. Along these lines, keeping the same baseline identification scheme, the model is estimated using non-primary real GDP growth instead of total real GDP growth.

Figure 7 shows the IRFs for real (total and non-primary) GDP growth and bank credit. The solid line represents the IRFs obtained with the model that uses total real GDP growth, and the dashed line represents the IRFs obtained with the model that uses non-primary real GDP growth. Given that this analysis considers a different variable in each model (output), it is nec-

9 There are two possible effects on inflation. The first one occurs on the demand side. Higher (lower) AD, reflected in faster (slower) GDP growth, increases (decreases) inflation. The second effect occurs on the side of production costs. Higher (lower) credit costs and lower (higher) credit growth hinder (facilitate) access to financing, thereby increasing (reducing) production costs and inflation. 
essary to normalize the IRFs; i.e., in each model the IRFs are normalized to a 100-basis point adverse shock on bank credit growth in the impact period.

Figure 7 shows that in both models an adverse LS shock causes a contraction in the pace of GDP growth. Comparing the IRFs for output, the shock causes 40- and 20-basis point contractions using non-primary and total real GDP growth, respectively. This provides empirical evidence that non-primary industries are more linked to the banking system. Therefore, in case of an adverse LS shock, it is more convenient to note the behavior of non-primary real GDP growth to identify and/or measure the real consequences of the shock. Focusing on total real GDP growth may well underestimate the adverse impact originating in the bank loan market.

Figure 7. IRFs: Loan Supply Shock (Using Non-Primary GDP with Baseline Identification)

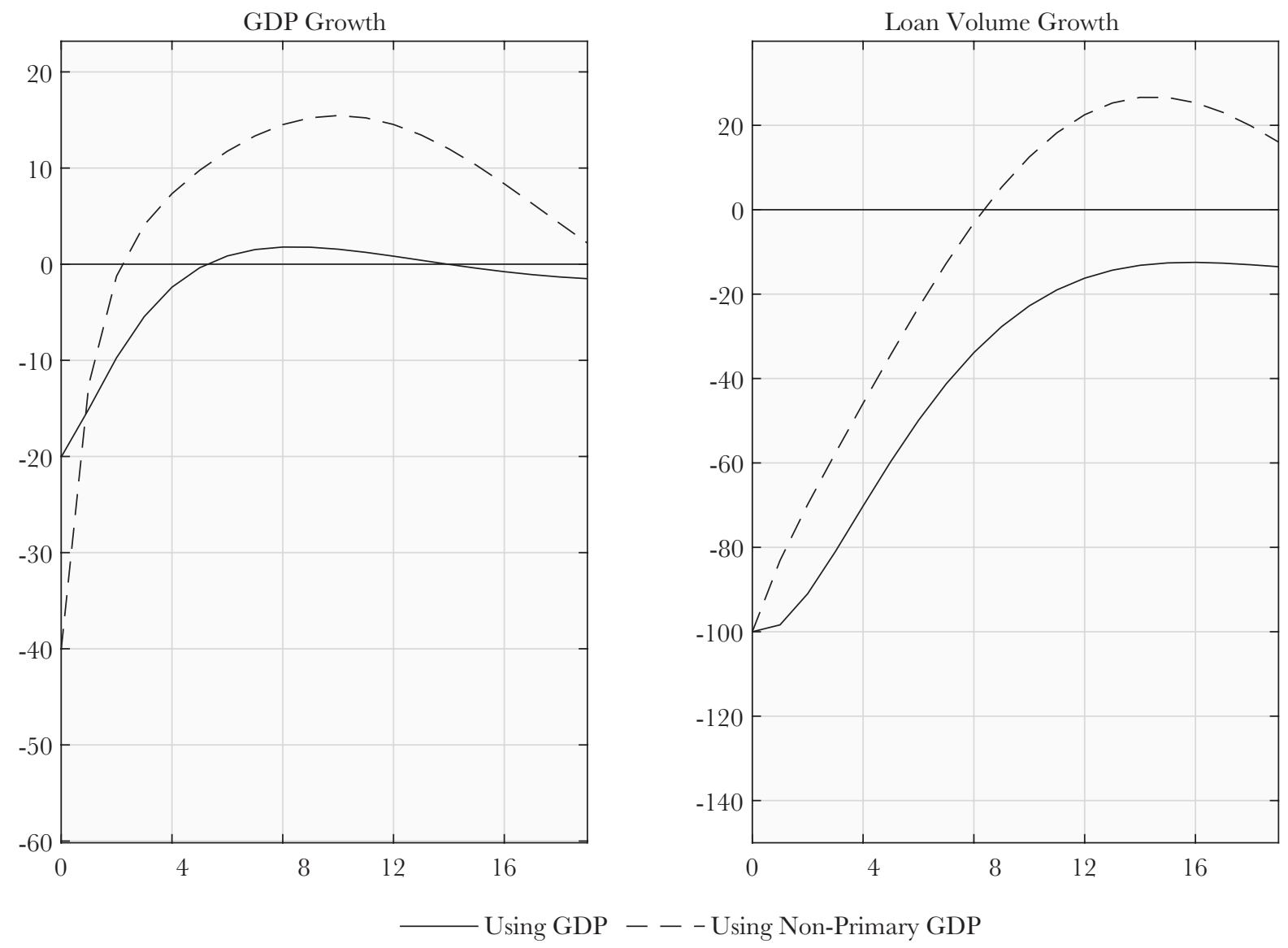

Regarding the FEVD analysis, an LS shock contributes more to explaining the variance of non-primary real GDP growth than total real GDP growth. Considering the 20 quarters analyzed, an LS shock explains $12.4 \%$ of the variance of non-primary real GDP growth, compared with $11.2 \%$ for total real GDP growth. The widest difference between both occurs in the first year (3.5 percentage points), where the LS shock explains $19.5 \%$ of the variability of non-primary real GDP growth, in contrast with $16.0 \%$ for total real GDP growth. Only in the second year does LS explain a greater proportion of total real GDP growth than non-primary real GDP growth $(12.5 \%$ and $10.2 \%$, respectively).

The results for the HD considering total real GDP growth in the model allows identification of three distinctive periods marked by adverse LS shocks. When the HD is analyzed considering non-primary real GDP growth, only the last two periods identified previously (2003Q3-2004Q3 and 2009Q1-2009Q $4^{10}$ ) are also prolonged (more than three consecutive quarters). The adverse LS shock reaches an average contribution of -5.4 percentage points of non-primary real GDP growth in 2003Q3-2004Q3, compared with just -2.0 percentage points for total real GDP

10 2010Q1 is not identified as part of an adverse LS shock, in contrast with the HD of the model that considered total real GDP growth. 
growth. In contrast, the adverse LS shock had a greater negative contribution to total than non-primary real GDP growth in the post-GFC period (-1.8 and -0.8 percentage points, respectively). Therefore, there is a clear difference in the contribution of the LS shock on non-primary real GDP growth compared with total real GDP growth: the contribution to the former was greater in 2003Q3-2004Q3, while the opposite occurred in the post-GFC period.

This difference is explained by the situation of the banking system. In the first period, Peru's banking system had been hit by the end-1990s crises and the political crisis of the 2000s, with several banks going broke. On the contrary, in the second episode (post-GFC) the resilience and sustainability of the banking system were not compromised. As non-primary real GDP is financed mainly through the banking system, developments in the latter are key to understanding why the contribution of the LS shock is greater for non-primary real GDP growth in the first episode than in the second one, compared with the contribution of the same shock on total real GDP growth.

\section{Other Shocks}

Figures 8-10 show the IRFs of real GDP growth, inflation, the interbank interest rate, domesticcurrency credit growth, the TAMN, and the credit spread to AD, AS, and MP shocks, respectively. The dotted lines represent the medians of the IRFs for the Bayesian estimation with 1,000 draws; the solid lines represent the IRFs obtained from the median model; and the edges of the shadowed area represent percentiles 16 and 84 of the IRFs obtained from the 1,000 draws.

Figure 8. IRFs: Aggregate Demand Shock (Baseline Identification). The dashed lines represent the median of IRFs calculated from BVAR estimation with 1,000 draws that satisfy the sign restrictions, while the solid lines represent the median model. The boundaries of shaded areas represent 16 and 84 percentiles.
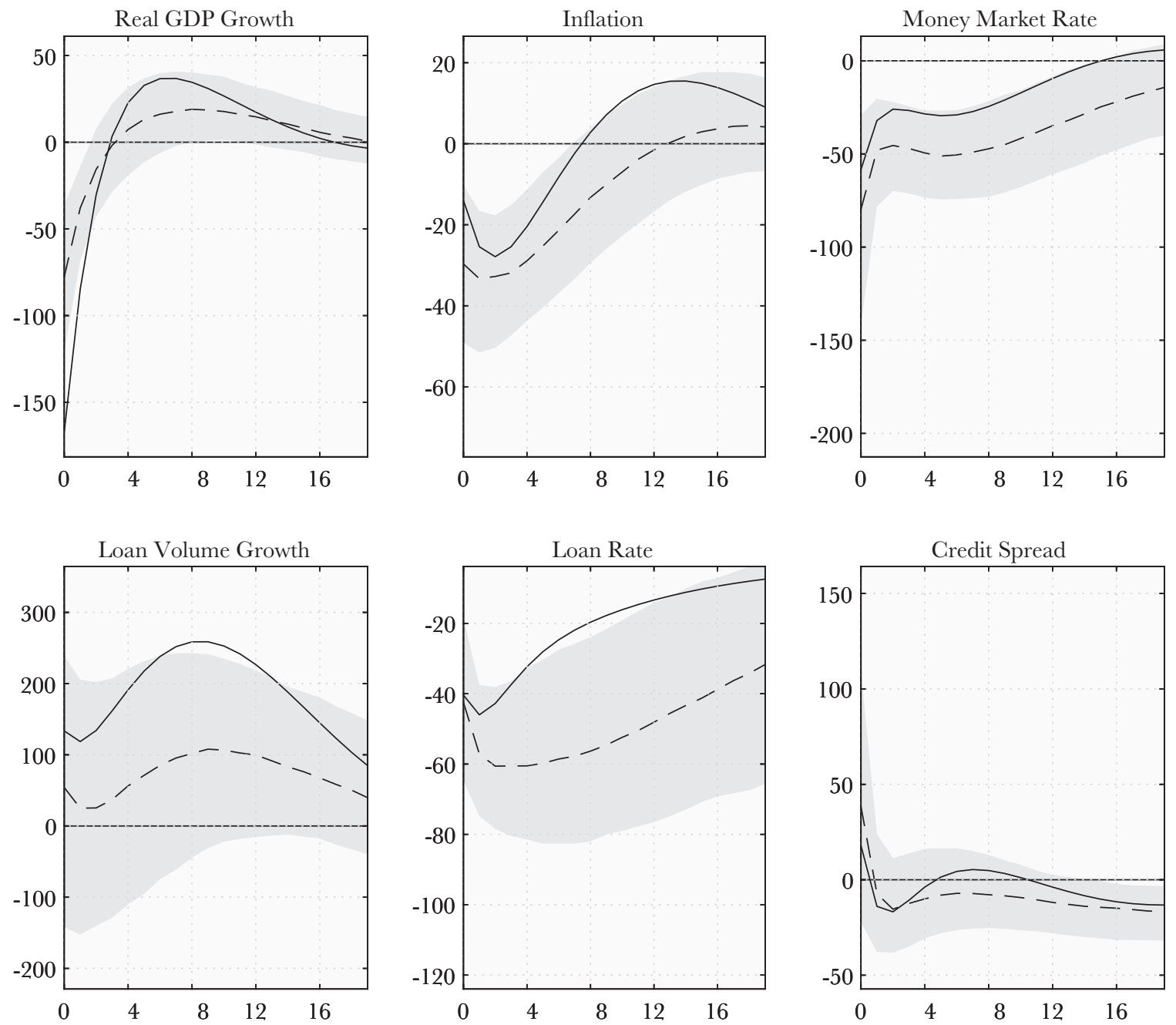
Figure 8 shows that an adverse AD shock contracts economic activity growth by 282 altogether during the first three quarters. In consequence, lower demand reduces inflation by 92 and 45 basis points during the first two years, respectively. In this context, the BCRP decides to reduce the interbank interest rate by 143,114 , and 76 basis points during the first three years ${ }^{11}$ to boost demand and underpin economic activity and inflation. In the bank market, the monetary measure reduces lending rates and increases credit growth during the period under analysis. The lower interbank interest rate reduces lending costs by 167, 107, and 68 basis points during the first three years through the monetary transmission channel. In turn, credit growth increases by 548,899 , and 1,012 basis points in response to lower lending costs during the first three years. However, although the result for bank loans corresponds to the median model, the zero value is part of the probability interval during the 20 quarters of the IRF for this variable.

Figure 9 suggests that an adverse AS shock (e.g., a production cost shock) increases inflation by 175 basis points during the first year and 27 basis points during the first half of the second year. In this context, the BCRP decides to raise the interbank interest rate by 421, 190, and 71 basis points during the first three years. The market response is an increase in lending costs and a reduction in credit growth. This considerable surge in inflation and the prompt monetary policy response (together with effective transmission to the bank market) discourages demand, in turn decelerating economic activity, mainly in the first three years (193, 264, and 155 basis points, respectively).

Figure 9. IRFs: Aggregate Supply Shock (Baseline Identification). The dashed lines represent the median of IRFs calculated from BVAR estimation with 1,000 draws that satisfy the sign restrictions, while the solid lines represent the median model. The boundaries of shaded areas represent 16 and 84 percentiles.
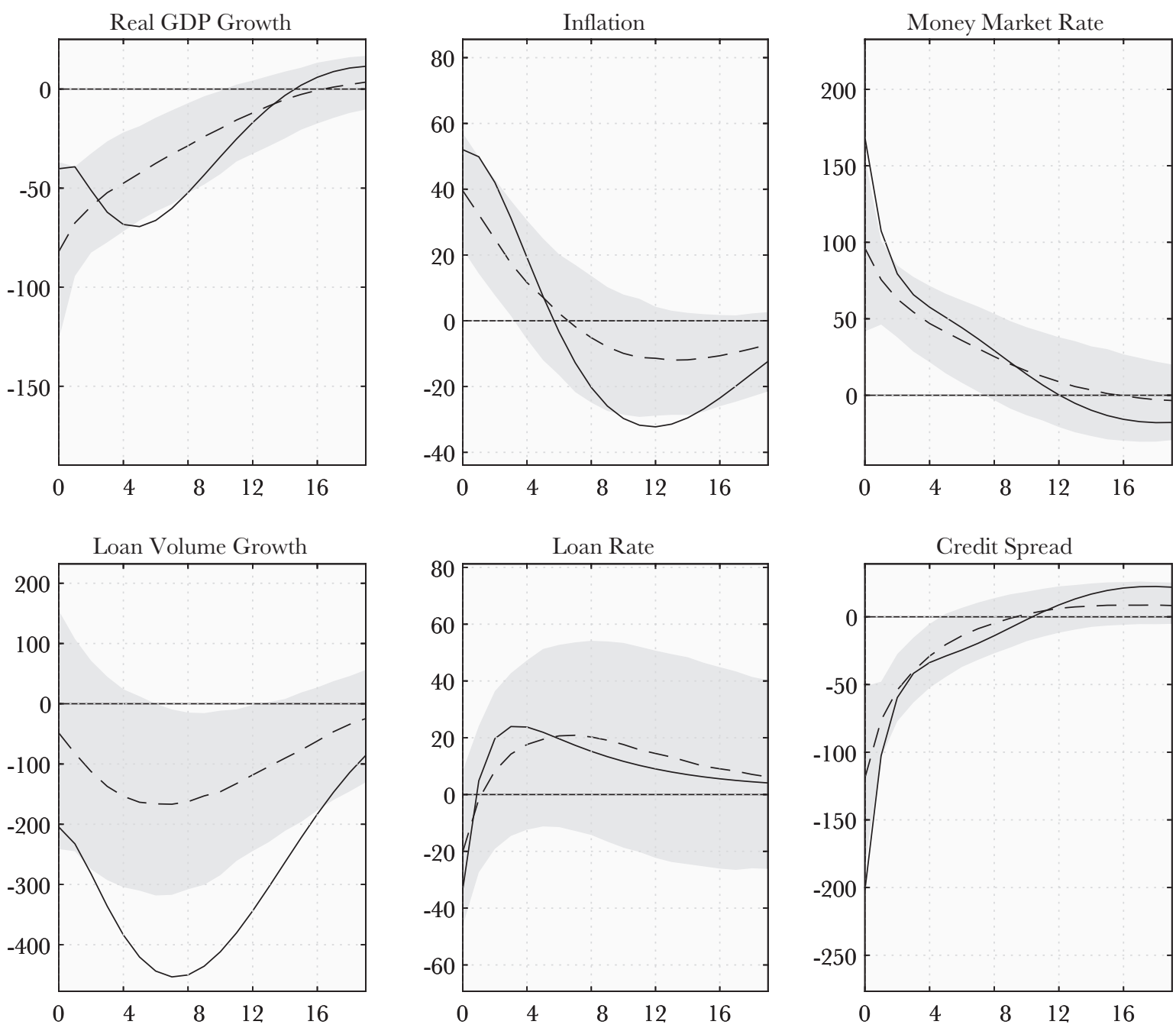

11 The reduction in the interbank interest rate during the fourth year was just 18 basis points. It does not reach the minimum change in BCRP monetary measures (25-basis point movements). 
Finally, Figure 10 shows the IRFs to a MP shock. The latter causes a persistent increase, although at a slower pace, in the interbank interest rate during the 20 quarters and with greater relevance during the first two years (340 and 168 basis points, respectively). In this context, the TAMN rises, although less than the interbank rate, and therefore the credit spread drops; i.e., the MP shock increases banks' financing costs (the interbank rate) more than the TAMN. This implies that banks give up profits to preserve credit growth (hence the fact that the zero value is part of the probability interval in the IRF of bank credit volume during the five years analyzed). In the real sector, higher bank financing costs reduce real GDP growth. As a result of higher financing costs and lower economic activity growth, inflation falls by 74 and 34 basis points during the first two years.

Figure 10. IRFs: Monetary Policy Shock (Baseline Identification). The dashed lines represent the median of IRFs calculated from BVAR estimation with 1,000 draws that satisfy the sign restrictions, while the solid lines represent the median model. The boundaries of shaded areas represent 16 and 84 percentiles.
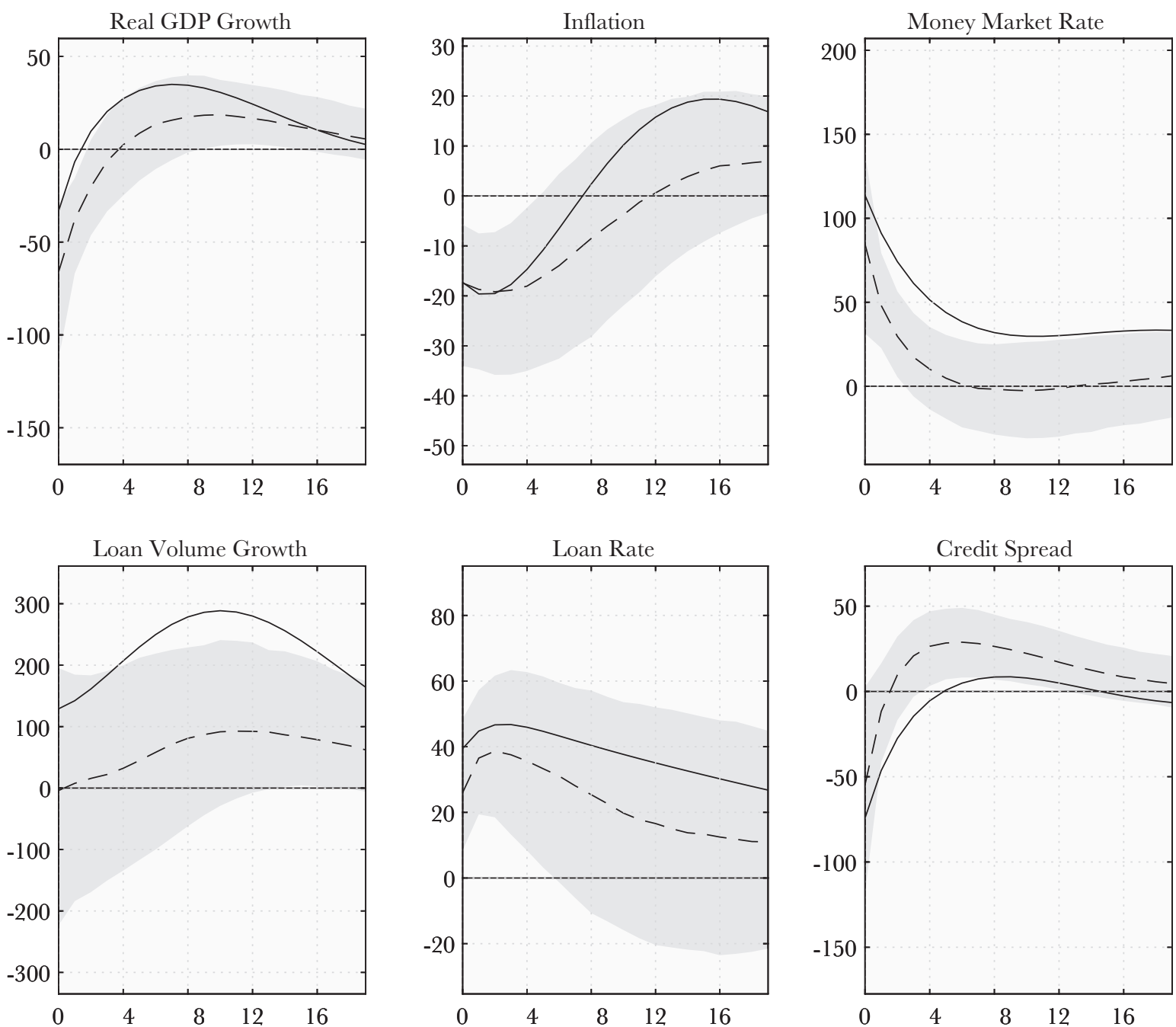

Summarizing, the AD, AS, and MP shocks identified in this paper are relevant for the variablesconsidered and are closely in line with economic theory. Particularly, the identification of shocks contributes to identifying LS shocks more accurately.

\section{Conclusions}

The main goal of this paper is identifying the importance of adverse LS shocks (e.g., during the GFC) on the main macroeconomic aggregates. To this end, a BVAR model for Peru's economy with sign restrictions is used. Additionally, in order to identify LS shocks accurately, MP, AD, and AS shocks are also identified. Export price index growth is added to control for the effect of 
external shocks. The estimation and identification of the model throw three main results. First, in line with the result for the IRFs, a contractionary LS shock has an adverse effect on the bank market (domestic-currency bank credit growth decreases and lending costs rise) and on real GDP growth. Particularly, bank credit growth in the impact period contracts by 372 basis points, the TAMN rises by 42 basis points, and real GDP growth falls by 75 basis points. This happens despite a prompt response from the monetary authority, which reduces the interbank rate by 74 and 40 basis points during the first two quarters, respectively.

Second, the result for the FEVD shows that, while AD and AS shocks explain a considerable part of the forecast variance of real GDP growth, LS shock explain on average, during the 20 quarters considered, around $11.2 \%$ (higher than $6.6 \%$ of the variance explained by the MP shock).

Third, the result for the HD indicates that, in addition to serving as a channel for the main macroeconomic (AD, AS, and MP) shocks, the banking system is responsible for a substantial part of the behavior of real GDP growth. LS shocks played an important role in the last two international crises affecting Peru's economy (the end-1990s and 2008-2009 crises). In 1999Q22000Q1 the adverse LS shock is responsible for a 190-basis point fall on average in real GDP growth, while in 2009Q1-2010Q1 it caused a 180-basis point decrease.

Additionally, the calculated response of real GDP growth to an adverse LS shock is robust to several alternative identification schemes. All identification schemes point to a reduction in the pace of economic growth. While there are differences in the magnitude and duration of the impact of adverse LS shock on real GDP, the conclusions about the direction of the impact are the same.

In this regard, it is necessary to pay attention to banking system conditions when monitoring the behavior of the overall economy. The results obtained indicate that LS shocks play an important role in the pace of economic activity. Moreover, the sensitivity analysis suggests that the impact of an LS shock is more considerable in the non-primary sector. Along these lines, policy-makers should know and anticipate the behavior of the banking system to take prompt action in the face of unanticipated shocks.

\section{References}

Atta-Mensah, J., and Dib, A. (2008), "Bank lending, credit shocks, and the transmission of Canadian monetary policy," International Review of Economics and Finance 17(1), 159-176.

Bańbura, M., Giannone, D., and Riechlin, L. (2008), "Large Bayesian VARs," European Central Bank, Working Paper 966.

Bernanke, B. S., and Blinder, A. S. (1988), "Credit, money, and aggregate demand," National Bureau of Economic Research WP 2534.

Bernanke, B. S., Gertler, M., and Gilchrist, S. (1996), "The flight to quality and the financial accelerator," Review of Economics and Statistics 78(1), 1-15.

Bernanke, B. S., Gertler, M., and Gilchrist, S. (1999), "The financial accelerator in a quantitative business cycle framework," Handbook of Macroeconomics 1, 1341-1393.

Busch, U., Scharnagl, M., and Scheithauer, J. (2010), "Loan supply in Germany during the financial crisis," Discussion Paper Series 1: Economic Studies 5/2010.

Canova, F. (2011). Methods for Applied Macroeconomic Research. Princeton: Princeton University Press.

Canova, F., and Paustian, M. (2011). "Business cycle measurement with some theory," fournal of Monetary Economics 58(4), 345-361. 
Castillo, P., and Salas, J. (2010), "Los términos de intercambio como impulsores de fluctuaciones económicas en economías en desarrollo: Estudio empírico", Centro de Estudios Monetarios Latinoamericanos, Premio de Banca Central Rodrigo Gómez.

Cúrdia, V., and Woodford, M. (2010), "Credit spreads and monetary policy," Fournal of Money, Credit and Banking 42(6), 3-35.

Dancourt, O. (2012), "Crédito bancario, tasa de interés de política y tasa de encaje en el Perú", Departamento de Economía, Pontificia Universidad Católica del Perú, Working Paper 342.

De Bond, G. J. (2005), "Interest rate pass-through: empirical results for the Euro Area," German Economic Review 6(1), 37-78.

Espino, F. (2013), "Hechos Estilizados del Sistema Bancario Peruano", Banco Central de Reserva del Perú WP 2013-005.

Faust, J., and Leeper, E. M. (1997), "When do long-run identifying restrictions give reliable results?", Journal of Business and Economic Statistics 15(3), 345-353.

Fry, R., and Pagan, A. (2011), "Sign restrictions in structural vector autoregressions: A critical review," Journal of Economic Literature 49(4), 938-60.

Gambetti, L., and Musso, A. (2017), "Loan supply shocks and the business cycle," Fournal of Applied Econometrics 32(4), 764-782.

Gerali, A., Neri, S., Sessa, L., and Signoretti, F. M. (2010), "Credit and Banking in a DSGE Model of the Euro Area," Fournal of Money, Credit and Banking 42(6), 108-141.

Gertler, M., and Karadi, P. (2011), "A model of unconventional monetary policy," fournal of Monetary Economics 58(1), 17-34.

Gilchrist, S., Ortiz, A., and Zakrajsek, E. (2009), "Credit Risk and the Macroeconomy: Evidence from an Estimated DSGE Model," Unpublished manuscript, Boston University.

Goodfriend, M., and McCallum, B. T. (2007), "Banking and interest rates in monetary policy analysis: A quantitative exploration," Journal of Monetary Economics 54(5), 1480-1507.

Groen, J. J. J. (2004), "Corporate Credit, Stock Price Inflation and Economic Fluctuations," Applied Economics 36(18), 1995-2006.

Guevara, C. and Rodríguez, G. (2018), "The Role of Loan Supply Shocks in Pacific Alliance Countries: A TVP-VAR-SV Approach," Working Paper 467, Department of Economics, Pontificia Universidad Católica del Perú.

Guevara, C. and Rodríguez, G. (2020), "The role of credit supply shocks in pacific alliance countries: A TVP-VAR-SV Approach," North American Fournal of Economics and Finance 52, 101140 .

Hristov, N., Hülsewig, O., and Wollmershäuser, T. (2012). "Loan supply shocks during the financial crisis: Evidence for the Euro area," Journal of International Money and Finance 31(3), 569-592.

Kadiyala, K. R. and Karlsson, S. (1997), "Numerical methods for estimation and inference in Bayesian VAR-models," Fournal of Applied Econometrics 12(2), 99-132.

Kiyotaki, N., and Moore, J. (1997), "Credit cycles," Gournal of Political Economy 105(2), 21 1-248.

Koop, G., and Korobilis, D. (2010). "Bayesian multivariate time series methods for empirical macroeconomics," Foundations and Trends in Econometrics 3(4) 267-358.

Litterman, R. B. (1986), "Forecasting with Bayesian vector autoregressions - five years of experience," Fournal of Business and Economic Statistics 4(1), 25-38. 
Musso, A., Neri, S., and Stracca, L. (2011), "Housing, consumption and monetary policy: How different are the US and the euro area?", fournal of Banking and Finance 35(11), 3019-3041.

Ng, S. and Perron, P. (1995), "Unit Root tests in ARMA Models with Data Dependent Methods for the Selection of the truncation Lag," Fournal of the American Statistical Association 90, 268281.

Ng, S. and Perron, P. (2001), "Lag Length Selection and the Construction of Unit Root Tests with Good Size and Power," Econometrica 69, 1519-1554.

Nolazco, J. L., Lengua-Lafosse, P., and Céspedes N. (2016), "Contribución de los choques externos en el Crecimiento Económico del Perú: un modelo semi-estructural”, Banco Central de Reserva del Perú WP 2016-006.

Paustian, M. (2007), "Assessing sign restrictions," The BE Journal of Macroeconomics 7(1) Article 23.

Peersman, G. (2005), "What caused the early millennium slowdown? Evidence based on vector autoregressions," Fournal of Applied Econometrics 20(2), 185-207.

Peersman, G., and Straub, R. (2006), "Putting the New Keynesian Model to a Test," IMF Working Papers 06/135.

Pérez-Forero, F. and Vega, M. (2014), "The Dynamic Effects of Interest Rates and Reserve Requirements", Banco Central de Reserva del Perú WP 2014-018.

Rodríguez, G., Villanueva, P. and Castillo Bardalez, P. (2018), "Driving Economic Fluctuations in Peru: The Role of the Terms of Trade," Empirical Economics 55(3), 1089-1119. 